\title{
Efektifitas Penggunaan Rantai Pengaman pada Rangkaian Kereta
}

\author{
Erfianto R Chan, Eky Hezkiel Jeremy, Tertib Sinulingga \\ KERETA API INDONESIA PERSERO \\ Email: Erfianto79@gmail.com
}

\begin{abstract}
Abstrak
Tujuan penelitian ini adalah untuk menguji efektifitas penggunaan rantai pengaman pada rangkaian kereta. Penelitian ini menggunakan jenis penelitian kualitatif dengan pendekatan analisis deskriptif. Data yang digunakan berjenis data kualitatif berupa data primer dan data sekunder yang digunakan sebagai petunjuk untuk mengetahui seberapa pentingnya penggunaan rantai pengaman dan kelayakan alat perangkai yang digunakan pada saat ini untuk menarik rangkaian kereta serta sistem pengereman. Berdasarkan hasil analisa dan pembahasan yang telah dilakukan maka dapat diambil kesimpulan sebagai berikut: 1) Putusnya rangkaian kereta dapat terjadi apabila tidak sesuainya prosedur perawatan yang dilakukan dengan semestinya, sehingga membuat menurunnya kualitas atau kemampuan dari sarana dan prasarana yang tersedia; 2) Alat perangkai otomatis tetap kuat untuk menarik rangkaian pada kelandaian $33 \%$ dengan kecepatan maksimal 35 km/jam; 3) Bila terjadi putusnya alat perangkai maka akan terjadi sistem pengereman otomatis fail safe yang menurut perhitungan tidak larat dan tidak tergelincir dan dapat untuk menghentikan kereta pada kelandaian $33 \%$; dan 4) Gaya tarik maksimal yang bekerja pada rantai pengaman hanya sebesar14.700 kg dimana tidak akan kuat untuk menarik beban kereta pada kelandaian $33 \%$ sebesar $16.069 \mathrm{~kg}$ sehingga akan terputus.
\end{abstract}

Kata Kunci: Efektifitas, Penggunaan, Rantai Pengaman, Kereta Api.

\section{Abstract}

The purpose of this study was to test the effectiveness of the use of safety chains on a train circuit. This research uses qualitative research with descriptive analysis approach. The data used are qualitative data in the form of primary data and secondary data that is used as a guide to find out how important the use of safety chains and the feasibility of the coupling devices currently used to pull the train circuit and braking system is. Based on the results of the analysis and discussion that has been carried out, the following conclusions can be drawn: 1) The breakdown of the train circuit can occur if the maintenance procedures are not properly carried out, resulting in a 
decrease in the quality or ability of the available facilities and infrastructure; 2) The automatic coupler remains strong to pull the circuit at a slope of $33 \%$ with a maximum speed of $35 \mathrm{~km} / \mathrm{h}$; 3 ) If the coupling device is broken, there will be a fail safe automatic braking system which, according to calculations, does not slip and does not slip and can stop the train at a slope of 33\%; and 4) the maximum tensile force acting on the safety chain is only 14,700 kg which will not be strong enough to pull the train load at a 33\% slope of 16,069 $\mathrm{kg}$ so it will be disconnected.

Keywords: Effectiveness, Use, Safety Chain, Train.

\section{A. PENDAHULUAN}

Transportasi merupakan media perantara untuk melakukan perpindahan manusia dan barang dari suatu tempat ke tempat yang lain sesuai dengan sifat manusia yang terus bergerak dan melakukan perpindahan. Perpindahan tersebut akan berpengaruh pada beberapa aspek kehidupan baik ekonomi, politik, sosial dan budaya. Perkembangan berbagai aspek tersebut salah satunya dipengaruhi oleh faktor kemajuan sektor transportasi. Kemajuan transportasi dapat diindikasikan melalui beberapa indikator yaitu kapasitas yang tersedia, kemudahan aksesibilitas, kualitas pelayanan dan tingkat keselamatan serta keamanan.

Transportasi kereta api merupakan salah satu moda transportasi darat yang memiliki keunggulan dibanding dengan moda angkutan darat yang lain. Salah satu keunggulan kereta api antara lain dapat mengangkut penumpang dalam jumlah yang besar dengan waktu yang relatif singkat serta tingkat keselamatan dan keamanan yang tinggi. Sarana dan prasarana yang baik serta didukung dengan sistem operasi dan sumber daya manusia yang memadai.

Untuk mewujudkan hal tersebut, terutama dalam hal efisiensi biaya pengadaan dan perawatan sarana kereta api dibutuhkan beberapa tindakan perubahan pada perangkaian kereta api tanpa menghilangkan faktor keselamatan dan kenyamanan yaitu, dalam peniadaan penggunaan rantai pengaman pada rangkaian kereta. menurut hasil peneltian yang telah saya lakukan selama kurang lebih 2 bulan di daop 8 Surabaya bahwa pada rangkaian kereta api telah menggunakan sistem fail safe, yang dimana pada saat rangkaian kereta api terlepas maka sistem pengereman akan terjadi di seluruh rangkain termasuk lokomotif. Dan juga sistem pengaman pada perangkay mekanik otomatis sudah sangat kuat bila terus dalam perawatan. Sehingga keberadaan rantai pengaman pada sambungan kereta kurang efektif karena telah memiliki keamanan ganda ditambah dengan kekuatan kopler yang sudah cukup memadai untuk menarik kereta.

Maksud dan tujuan dari penulisan Kertas Kerja Wajib ini adalah untuk mengetahui pertambahan percepatan perangkaian pada saat merangkai kereta api dengan cara meniadakan rantai pengaman pada sambungan kereta. Kemudian untuk mengetahui keuntungan-keuntungan apa saja yang dapat ditimbulkan dari peniadaan rantai pengaman pada rangkaian kereta. Selain itu memberitahukan kepada pembaca dari kekuatan alat perangkai yang digunakan pada kereta saat ini, serta keamanan sistem pengereman fail safe yang terjadi pada saat terputusnya alat perangkai tersebut sehingga memungkinkan ditiadakannya rantai pengaman untuk menunjang keuntungankeuntungan yang akan terjadi: 1) Mengetahui kekuatan pengereman yang ada di kereta api; 2) 
Mengetahui kekuatan alat perangkai mekanik otomatis yang digunakan pada rangkaian kereta; 3) Mengetahui kemanan sistem fail safe pada kereta api.

Dalam penulisan Kertas Kerja Wajib (KKW) ini, penelitian ini dilakukan untuk mengetahui keuntungan dari peniadaan penggunaan rantai pengaman pada rangkaian kereta, dengan mengetahui apakah kekuatan dari alat perangkai serta sistem fail safe sudah cukup memadai dalam bidang keselamatan kereta api.

\section{B. LITERATUR REVIEW}

\section{Sarana Lokomotif}

Lokomotif adalah bagian dari rangkaian kereta api di mana terdapat mesin yang berfungsi untuk menggerakkan kereta api. Lokomotif dibagi menjadi beberapa jenis berdasarkan spesifikasi mesin, yaitu:

Lokomotif uap : Merupakan cikal bakal mesin kereta api. Uap yang dihasilkan dari pemanasan air yang terletak di ketel uap digunakan untuk menggerakkan torak atau turbin dan selanjutkan disalurkan ke roda. Bahan bakarnya bisanya dari kayu bakar atau batu bara.

Lokomotif diesel mekanis : Menggunakan mesin diesel sebagai sumber tenaga yang kemudian ditransfer ke roda melalui transmisi mekanis. Lokomotif ini biasanya bertenaga kecil dan sangat jarang karena keterbatasan kemampuan dari transmisi mekanis untuk dapat mentransfer daya.

Lokomotif diesel elektrik : Pada Lokomotif ini Mesin diesel dipakai untuk memutar generator agar mendapatkan energi listrik. Listrik tersebut dipakai untuk menggerakkan motor listrik besar yang langsung menggerakkan roda.

Lokomotif diesel hidraulik : Lokomotif ini menggunakan tenaga mesin diesel untuk memompa oli dan selanjutnya disalurkan ke perangkat hidraulik untuk menggerakkan roda. Lokomotif ini tidak sepopuler lokomotif diesel elektrik karena perawatan dan kemungkinan terjadi problem besar.

Lokomotif listrik : Lokomotif ini adalah lokomotif yang paling populer. Prinsip kerjanya hampir sama dengan lokomotif diesel elektrik, tetapi tidak menghasilkan listrik sendiri. Listriknya diperoleh dari kabel transmisi di atas jalur kereta api. Jangkauan lokomotif ini terbatas hanya pada jalur yang tersedia jaringan transmisi listrik penyuplai tenaga.

Lokomotf juga dibagi menjadi beberapa jenis berdasarkan konfigurasi sumbu/as roda lokomotif, yaitu: 1) kode B artinya lokomotif dengan 2 roda penggerak atau Bo-Bo; 2) kode C artinya lokomotif dengan 3 roda penggerak atau $\mathrm{Co}-\mathrm{Co} ; 3)$ kode $\mathrm{BB}$ artinya lokomotif bergandar 22 jadi dengan roda penggerakada 4 as roda atau memiliki 8 roda; 4) kode CC artinya lokomotif bergandar 33 jadi total penggeraknya ada 6 as roda atau memiliki 12 roda; 5) kode D artinya lokomotif bergandar 4 loko jenis ini biasanya hanya memiliki gandar tunggal sehingga total penggeraknya ada 4 as roda dengan jumlah roda 8.

Berikut adalah jenis lokomotif CC yang dimiliki DAOP 8 Surabaya: 
Lokomotif Tipe CC 201. Armada lokomotif CC 201 yang dimiliki oleh DAOP 8 Surabaya berjumlah 17 unit. Penggunaan lokomotif ini digunkan untuk menarik rangkaian KA lokal, rangkaian KA ekonomi, dan untuk dinas langsir.

Lokomotif Tipe CC 203. Armada lokomotif CC 201 yang dimiliki oleh DAOP 8 Surabaya berjumlah 10 unit. Penggunaan lokomotif ini digunkan untuk menarik rangkaian KA lokal, rangkaian KA campuran, rangkaian KA bisnis, rangkaian KA ekonomi, dan untuk dinas langsir.

Lokomitf tipe CC 206. Armada lokomotif CC 201 yang dimiliki oleh DAOP 8 Surabaya berjumlah 10 unit. Penggunaan lokomotif ini digunkan untuk menarik rangkaian KA BBM, rangkaian KA campuran, dan rangkaian KA eksekutif.

\section{Aspek Legalitas}

Untuk mendukung penyusunan penelitian ini, makan diperlukan suatu hal-hal atau teori yang berkaitan dengan permasalahan dan ruang lingkup pembahasan sebagai landasan dalam penyusunan penelitian ini.

Undang-undang Nomor 23 Tahun 2007 Tentang Perkeretaapian. Dalam undang-undang ini yang dimaksud dengan Pasal 1 ayat: 1) Perkeretaapian adalah satu kesatuan sistem yang terdiri dari atas prasarana, saran, dan sumber daya manusia, serta norma, kriteria, persyaratan, dan prosedur untuk penyelenggaraan transportasi kereta api; 2) Kereta api adalah saran perkeretaapian dengan tenaga gerak, baik berjalan sendiri maupun dirangkaikan dengan sarana perkeretaapian lainnya, yang akan ataupun sedang bergerak di jalan rel yang terkait dengan perjalanan kereta api; 3) Fasilitas penunjang kereta api adalah segala sesuatu yang melengkapi penyelenggaraanangkutan kereta api yang dapat memberikan kemudahan, kenyamanan, dan keselamatan bagi pengguna jasa kereta api; 4) Pengguna jasa adalah setiap orang dan / atau badan hukum yang menggunakan jasa angkutan kereta api, baik untuk angkutan orang maupun barang; dan 5) Angkutan kereta api adalah kegiatan pemindahan orang dan/atau barang dari satu tempat ke tempat lain dengan menggunakan kereta api.

Pasal 133 ayat (1) Dalam penyelenggaraan pengangkutan orang dengan kereta api, Penyelenggara Sarana Perkeretaapian wajib: a) mengutamakan keselamatan dan keamanan orang; b) mengutamakan pelayanan kepentingan umum; c) menjaga kelangsungan pelayanan pada lintas yang ditetapkan; d) mengumumkan jadwal perjalanan kereta api dan tariff angkutan kepada masyarakat; dan e) mematuhi jadwal keberangkatan kereta api.

Peraturan Pemerintah Nomor 72 Tahun 2009 Tentang Lalu Lintas Dan Angkutan Kereta Api Pasal 133 ayat : a) Pengoperasia kereta api harus memenuhi standar pelayanan minimum; b) Standar pelayanan minimum sebagaimana dimaksud pada ayat (1) meliputi: standar pelayanan minimum di stasiun kereta api; dan standar pelayanan minimum dalam perjalanan. Pada Pasal 134 ayat (2) Standar pelayanan minimum dalam perjalanan kereta sebagaimana dimaksud dalam Pasal 133 ayat (2) huruf b terdiri atas :untuk kereta api antarkota paling sedikit meliputi: pintu dan jendela; tempat duduk dengan kontruksi tetap yang mempunyai sandaran dan nomor tempat duduk; toilet dilengkapi dengan air sesuai dengan kebutuhan; lampu penerangan; kipas angin; rak bagasi; restorasi; informasi stasiun yang dilewati/disinggahi secara berurutan; fasilitas khusus dan 
kemudan bagi penyandang cacat, wanita hamil, anak di bawah lima tahun, orang sakit, dan orang lanjut usia; fasilitas kesehatan, keselamatan, dan keamanan; nama dan nomor urut kereta; informasi gangguan perjalanan kereta api; dan ketepatan jadwal perjalanan kereta api.

\section{Aspek Teoritis}

Menurut Salim (2000), Transportasi adalah kegiatan pemindahan barang (muatan) dan penumpang dari suatu tempat ke tempat lain. Dalam transportasi ada dua unsur yang terpenting yaitu pemindahan/pergerakan dan secara fisik mengubah tempat dari barang dan penumpang ke tempat lain.

Menurut Soegijatna Tjakranegara (1995), Transportasi merupakan proses memindahkan barang (commodity of goods) serta penumpang dari sebuah tempat menuju tempat lain. Sehingga pengangkut akan menghasilkan jasa angkutan maupun produksi jasa untuk masyarakat yang memerlukan dalam pengiriman atau pemindahan barang.

Menurut Philip Kotler, Menejemen Pemasaran (2002) Pelayanan adalah setiap tindakan atau kegiatan yang dapat ditawarkan oleh suatu pihak kepada pihak lain, yang pada dasarnya tidak berwujud dan tidak mengakibatkan kepemilikan apapun. Kualitas pelayanan adalah segala bentuk aktivitas yang dilakukan oleh perusahaan guna memenuhi harapan konsumen. Pelayanan dalam hal ini diartikan sebagai jasa atau service yang disampaikan oleh pemilik jasa yang berupa kemudahan, kecepatan, hubungan, kemampuan, dan keramahtamahan yang ditunjukkan melalui sikap dan sifat dalam memberikan pelayanan untuk kepuasan konsumen. Definisi kualitas pelayanan diartikan sebagai upaya pemenuhan kebutuhan dan keinginan konsumen serta ketepatan penyampaian dalam mengimbangi darapan konsumen. Kualitas pelayanan (service quality) dapat diketahui dengan cara membandingkan presepsi para konsumen atas pelayanan yang nyata mereka terima/diperoleh dengan pelayanan yang sesungguhnya mereka harapkan terhadap atributatribut pelayanan suatu perusahaan.

Menurut Hidayat (1986), Efektivitas adalah suatu ukuran yang menyatakan seberapa jauh target (kuantitas,kualitas dan waktu) telah tercapai. Dimana makin besar presentase target yang dicapai, makin tinggi efektivitasnya. Judul tugas yang saya ambil menyangkut tentang keefektifan penggunaan rantai pengaman yang ada pada rangkaian kereta. Menurut saya hal ini kurang efektif karena pada kereta api telah didukung oleh kekuatan alat perangkai/kopler yang sangat memadai untuk menarik rangkaian kereta api, dan juga ada sistem keamanan ganda yaitu sistem fail safe, dimana rangkaian kereta dari lokomotif hingga kereta paling belakang melakukan pengereman secara otomatis jika salah satu selang angin yang ada pada rangkaian terputus yang menyebabkan kereta api tersebut akan langsung berhenti. Dari peniadaan ini akan memperoleh beberapa keuntungan yaitu, menambah kecepatan waktu merangkai dan mengurangi biaya perawatan dari rantai tersebut, tanpa mengurangi faktor keselamatan pada kereta tersebut.

\section{HASIL DAN PEMBAHASAN}

Penelitian ini menggunakan jenis penelitian kualitatif dengan pendekatan analisis deskriptif. Data yang digunakan berjenis data kualitatif berupa data primer dan data sekunder yang digunakan 
sebagai petunjuk untuk mengetahui seberapa pentingnya penggunaan rantai pengaman dan kelayakan alat perangkai yang digunakan pada saat ini untuk menarik rangkaian kereta serta sistem pengereman fail safe yang terjadi apabila terjadinya kemungkinan terkecil yaitu terputusnya rangkaian. Adapun tahapan rencana penelitian ini adalah tahap persiapan, pengumpulan data, analisis, dan akhir penulisan. Analisis data hasil penelitian menggunakan analisis kondisi eksisting.

\section{HASIL DAN PEMBAHASAN}

\section{Analisis Terputusnya Rangkaian Kereta Api}

Kejadian terputusnya rangkaian KA yang menggunakan alat perangkai mekanik otomatis pernah terjadi. Peristiwa tersebut meinmpa pada rangkaian KA BBR1. Terlepasnya rangkaian 16 gerbong KKBW di Km 19+2/3 dikarenakan terbukanya sambungan automatic coupler (boper). Hal ini tidak akan terjadi tanpa adanya gerakan/tarikan dari pengungkit stang pengunci automatic coupler (boper). Dengan kata lain coupler tersebut baru akan terlepas bila stang pengunci ditarik. Pada saat terlepasnya boper ini dapat diperkirakan bahwa selang/saluran airbrake masih tersambung. Saat rangkaian KA BBR1 maju menuju Stasiun Labuhan Ratu, selang yang masih tersambung langsung tertarik dan putus di dekat plugkraan KKBW 1064. Selang/saluran airbrake di KKBW 1064 yang terbuka menyebabkan 16 rangkaian gerbong KKBW tersebut dalam posisi rem mengikat. Selanjutnya tim penyelidik KNKT melakukan uji coba terhadap proses pelepasan boper (coupler) antar gerbong KKBW dengan cara melepaskan stang pengunci boper. Tim menemukan bahwa proses pelepasan coupler dapat dilakukan dengan mudah tanpa memerlukan keahlian ataupun pengetahuan khusus. Adanya sistem pengamanan sambungan antar gerbong yang lebih baik memerlukan kajian lebih lanjut. (sumber: LKKA KNKT 2006). Dari kejadian tersebut dapat dilihat bahwa terlepasnya kopler bukan terjadi karena ketidak mampuan kopler tersebut melainkan terlepasnya stang pengunci yang diduga sengaja dilakukan oleh orang yang tidak bertanggung jawab. Karena mudahnya stang pengunci tersebut dilepas tanpa keahlian khusus, maka harus meningkatkan pengamanan pada sambungan tersebut.

Untuk menganalisa putusnys rangkaian KA, disamping kekuatan alat perangkai maka sebagai bahan analisa pendukung adalah analisa terhadap perbedaan antara tinggi 2 (dua) alat perangkai yang saling tersambung satu sama lain. Kondisi tersebut merupakan potensi terjadi putusnya rangkaian dalam pengoperasiaan KA akibat adanya gerakan vertical berlebihan dalam kecepatan tertentu ketika KA menginjak jalan rel yang kondisi teknisnya kurang baik.

Berdasarkan Peraturan Dinas PT Kereta Api No PD 16 A dan PD 8 mengatur ketentuan tentang besar selisih tinggi 2(dua ) alat perangkai diatur dalam kondisi statis (sudah termasuk perbedaan tinggi rel, keausan roda, tanjakan, tikungan dan kondisi-kondisi lainnya.

Dari kasus-kasus diatas disimpulkan bahwa penyebeb putusnya rangkaian kereta disebabkan oleh beberapa faktor yaitu: 1) Perbedaan diameter roda yang extrim; 2) Adanya kegagalan pegas/lemahnya pegas yang digunakan karena telah memiliki jam pakai yang panjang; 3) Telah terjadi keasuan plat gesek yang berada dibawah kereta; 4) Adanya goncangan akibat jalan rel yang tidak rata sehingga terjadi perbedaan tinggi antara rangkaian kereta; dan 5) Longgarnya casing pal 
block dikarenakan pemakaian yang cukup lama. Semua kejadian di atas bisa teratasi bila melakukan perawatan yang benar mulai dari P1, P3, P6, P12 pada sarana maupun prasarana, karena pada kasus ini membuktikan bahwa putusnya rangkaian kereta bukan karena lemahnya kopler melainkan kelalaian dalam perawatan atau tidak sesuainya spesifikasi yang telah ditentukan.

\section{Analisis Sistem Pengereman Udara Tekan}

Dalam analsia kerja sistem pengeraman, yaitu menghapus tenaga gerak atau energy kinetic dengan memberikan perlawanan gesek yaitu dengan menekankan rem blok pada bidang jalan atau telapak roda. Pada kasus kereta berada pada miring dengan kemiring tertentu seperti gambar diatas maka gaya-gaya yang bekerja pada kereta adalah sebagai gambar berikut:

Gaya yang sejajar dengan bidang miring $\quad=\mathrm{Gr}$. sin $\mathrm{i}$

Gaya yang tegak lurus terhadap bidang miring $=\mathrm{Gr} . \cos \mathrm{i}$

Persentase pengereman disajikan dalam tabel berikut ini:

Tabel 1. Persentase pengereman

\begin{tabular}{|c|c|c|c|c|c|c|c|c|c|}
\hline \% & Jenis Pengereman & \multicolumn{7}{|c|}{ Persentase pengereman dan kecepatan yang diizinkan } \\
& & \multicolumn{7}{|c|}{ hingga Km/jam } \\
\hline & & 35 & 40 & 45 & 50 & 55 & 60 & 65 & 70 \\
\hline 20 & $\mathrm{R} / \mathrm{P}$ & 28 & 32 & 36 & 40 & 46 & 51 & 58 & 65 \\
\hline 22 & $\mathrm{R} / \mathrm{P}$ & 31 & 34 & 38 & 43 & 48 & 54 & 61 & 68 \\
\hline 25 & $\mathrm{R} / \mathrm{P}$ & 34 & 38 & 42 & 47 & 53 & 59 & 66 & 73 \\
\hline 30 & $\mathrm{R} / \mathrm{P}$ & 40 & 45 & 49 & 54 & 60 & 66 & 74 & 81 \\
\hline 35 & $\mathrm{R} / \mathrm{P}$ & 71 & 51 & 56 & 61 & 68 & 74 & 83 & 90 \\
\hline
\end{tabular}

Sumber: data diolah

Dalam analisa ini maka Persentase Pengereman $(\lambda)$ ditetapkan sesuai tabel persentase pengereman dengan memilih berdasarkan kepada: Kecepatan KA sebesar (35 km/jam) dan Gradient /Tanjakan Jalan ssebesar (33). Apabila Kereta api berada pada tanjakan diasasumsikan sebagaimana suatu benda berada pada bidang miring dengan gaya-gaya yang bekerja seperti pada gambar dibawah ini:

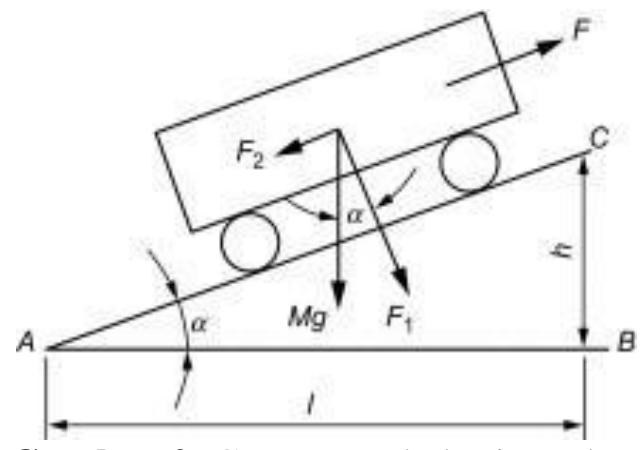

Dimana:

Gambar 2. Gaya yang bekerja pada sudut miring

$\mathrm{Fb}=$ Gaya Pengereman (Brake Force)

$\mathrm{i}=$ sudut kemiringan/tanjakan jalan rel 
$\mathrm{Gr}=$ Berat Rangkaian KA

\section{Analisis Penggunaan Rantai Pengaman}

Analisa kekuatan rantai pengaman adalah menghitung kekuatan rantai dalam menahan gaya beban kerja maksimum.

Rantai yang digunakan sebagai rantai pengaman rangkaian kereta api adalah rantai yang terbuat dari baja

Ketentuan rantai pengaman adalah sbb :

Jenis rantai pengaman $=9$ anting ( 9 eye chain)

Jumlah/ kereta $=4$ unit

Berat rantai $/ 1$ meter $=20,21 \mathrm{~kg}$

Diameter $\quad=26 \mathrm{~mm}\left(\mathrm{~A}=530,7 \mathrm{~mm}^{2}\right)$

Working limited load $=1.180 \mathrm{~kg}-7.350 \mathrm{~kg}$

Dari ketentuan diatas gaya tarik maksimal yang bekerja pada rantai pengaman sebesar 7.350 $\mathrm{kg}$, jika pada rangkaian satu ke rangkaian lainnya terdapat 2 rantai maka total gaya tarik rantai sebesar $14.700 \mathrm{~kg}$.

Analisa berat rantai pengaman terhadap perlawanan rangkain ka Analisa terhadap berat rantai pengaman dilakukan bertujuan untuk mengetahui tingkat perbedaan gaya perlawanan rangkaian yang timbul dan tingkat perbedaan daya/energi yang dibutuhkan antara rangkaian KA yang menggunakan rantai pengaman dengan rangkaian KA yang tidak menggunakan rantai pengaman: a) Berat rantai pengaman; b) Jumlah rantai pengaman setiap lok : 4; c) Jmlah rantai pengaman setiap kereta $=4$; d) Berat rantai pengaman setiap lokomotif $=80,4 \mathrm{~kg}$; dan e) Berat rantai pengaman pada setiap kerta $=80,4 \mathrm{~kg}$. Jika rantai pengaman dihilangkan maka daya tarik lokomotif akan semakin rendah yang menyebabkan lokomotif akan lebih efisien.

\section{E. KESIMPULAN}

Berdasarkan hasil analisa dan pembahasan yang telah dilakukan maka dapat diambil kesimpulan sebagai berikut: 1) Putusnya rangkaian kereta dapat terjadi apabila tidak sesuainya prosedur perawatan yang dilakukan dengan semestinya, sehingga membuat menurunnya kualitas atau kemampuan dari sarana dan prasarana yang tersedia; 2) Alat perangkai otomatis tetap kuat untuk menarik rangkaian pada kelandaian $33 \%$ dengan kecepatan maksimal 35 km/jam; 3) Bila terjadi putusnya alat perangkai maka akan terjadi sistem pengereman otomatis fail safe yang menurut perhitungan tidak larat dan tidak tergelincir dan dapat untuk menghentikan kereta pada kelandaian $33 \%$; dan 4) Gaya tarik maksimal yang bekerja pada rantai pengaman hanya sebesar14.700 kg dimana tidak akan kuat untuk menarik beban kereta pada kelandaian $33 \%$ sebesar $16.069 \mathrm{~kg}$ sehingga akan terputus. 


\section{DAFTAR PUSTAKA}

Undang - Undang Nomor 23 Tahun 2007 Tentang Perkeretaapian

Peraturan Pemerintah No. 72 Tahun 2009 tentang Lalu lintas dan Angkutan Kereta Api

Peraturan Mentri No. 63 Tahun 2019 tentang Standar dan Tata Cara Perawatan Prasarana Perkeretaapian

Ketetapan Mentri No. 41 Tahun 2010 tentang Standar Spesifikasi Teknis Kereta yang Ditarik Lokomotif

Peraturan Pemerintah No. 56 Tahun 2009 tentang Penyelenggaraan Perkeretaapian Hartono, AS, 2015. Lokomotif dan Kereta Rel Diesel di Indonesia Edisi 3, Jakarta. 